\title{
Analysis of e-government information resources and services in China
}

\author{
Yiqing $L U^{1,2, a}$ \\ ${ }^{1}$ Beijing Key Laboratory of Multimedia and Intelligent Software Technology \\ College of Metropolitan Transportation \\ Beijing University of Technology, Beijing. 100124, China \\ ${ }^{2}$ School of Information Management, Beijing Information Science and Technology University, \\ Beijing, 100192, China \\ aemail: luyiqing@126.com
}

Keywords: E-government; Information resources; Information services

\begin{abstract}
The ultimate significance of e-government is to provide information and services to public. This paper provides a comprehensive study and analysis to the current e-government website of all level government in China. Firstly the style of e-government information resources is described. The style is summarized from different aspects. Secondly the organization mode of e-government information resources is analyzed in detail. Then the present situation of e-government information services is described. The work can provide a reference for the e-government information resources organization, planning and website construction; also contribute to enhance the level of government information services.
\end{abstract}

\section{Introduction}

Electronic government (e-government) refers to government activities that take place by digital processes over a computer network, usually the Internet, between the government and members of the public and entities in the private sector, especially regulated entities [1]. These activities generally involve the electronic exchange of information to acquire or provide products or services, to place or receive orders, to provide or obtain information, or to complete financial transactions. The anticipated benefits of e-government include reduced operating costs for government institutions and regulated entities, increased availability since government services can be accessed from virtually any location, and convenience due to round-the-clock availability. In addition, electronic government provides direct communications between legislators and their constituents via e-mail.

The nature of e-government is to establish modern government management model which has users as center, application as soul, and its purpose is to bring convenience to public [2]. The functions of e-government are not limited to publish government related information. E-government will eventually achieve seamless integration of the government information resources and social information resources, so that the government can really achieve office automation, information management and scientific decision-making in the new management model. E-government has the potential to reduce costs, improve services, and bring transparency, and accountability to government, as well as control fraud and corruption.

Information resources refer to the strategic resources of the state, society and the organization, including text, audio-visual, print and electronic information and database [3]. Government information resources means the information generated in the work of government operations and its associated personnel, equipment, technical and financial elements of the set.

It is important for e-government is to provide information and services to public. Any ministry that delivers services directly to the public benefits the most. Ministries the deals directly with the citizenry are subject to scrutiny and, most importantly, to be effective in delivering their service, have to take into account the needs of the citizen. If the government is transparent and open in their dealings with the public, they will get proper feedback from citizens, which in turn increase efficiencies within their own ministries. This process then helps the ministry to create better 
programs to deliver their services and leads to economic savings because of the useful feedback from the citizen. To be effective in delivering an e-service, it has to meet the needs of the citizen and not solely the needs of a particular government ministry.

The direct connections between a government department and citizens, whether it be in the private sector, the academic world, civil society or NGOs, unions or associations and the individual citizen, eventually creates significant change in a society [4-5]. This change is the transfer of some of the traditional powers of government to groups and citizens in society. This has already been acknowledged by the United Nations and some countries that now recognize NGOs as a significant part of the power structure and decision-making process of organizations or in some cases, countries. This evolution is having long-term consequences as devolved power through the sharing of e-services entails the imparting of information and responses back from the citizen.

E-government has the potential to reduce costs, improve services, and bring transparency, and accountability to government, as well as control fraud and corruption. With the inter-time feature of network transmission, the own characteristics of electronic information resources provides unprecedented conditions to the building and sharing of government information resources [6-7]. With the implementation of electronic government information resources sharing, it's able to prevent duplication, excessive and improper construction, and gain largest financial interest with limit fund. It's linked to the enterprise, the public entity, the government departments at all levels and other institutions related to economic, cultural, political, legal, social security, management and other services. Its can be imagined that they contain rich content and performance records of a variety of forms. Therefore, it is necessary to analyze the basic model and type of the e-government information resources in China, to provide reference to the planning and management of e-government resources, and the construction of e-government website.

\section{E-government Information Resource Type}

E-government is a compact, efficient government operation mode which uses the modern information technology in its management and service functions. It realizes the restructuring optimization of the organization structure and the working process, and surpasses the restriction time, space and department division [8-9]. In China, after the phase of office automation, three gold project and government online project, e-government has entered the system integration and information resource integration phase.

The government information resources are those all produced in government interior or although produced outside the government but affect every government business activities. The government is the largest social information resource owner, producer, user and transporter, and plays a leading role to the social information resource development and utilization. Its service objects include government, enterprise and public. The government information resources have the following characteristics: amount of information is large, wide range and the higher requirements to information accuracy and security.

In this paper, we provide a comprehensive study and analysis to the current e-government website of all level government in China, including the Central People's government, the various ministries government, the local government and the embassies abroad [10]. And with reference to other e-government research, come out the following e-government analysis result. China's e-government information resources can be classified from different angles, as is shown in Table 1.

\section{Institutions Optimization Design}

The ball $R=21.6 \mathrm{~mm}, m_{b}=45 \mathrm{~g}$. To ensure the cue ball and pick and not run into low contact choose other parts of the cue for $w=16 \mathrm{~mm}$. From the law of conservation of energy, it is known that the lighter lift stick, the faster the speed at first, consider to pick cue the deformation of stress intensity factor, finally optimization for $m_{c}=34 \mathrm{~g}$. Since robot have play ball institutions, in order not to decorate with the wheel position conflict, only can pick the ball in play on electromagnetic valve

electromagnet institutions. According to the electromagnet diameter and robot's height, take 
$L=58 \mathrm{~mm}, h=19 \mathrm{~mm}$.

According to the above theory formula, let's take the part of determined and the other institutions into the condition, and let the rest of the adjustable parameters for quantitative analysis of the design. It can be found to pick the ball with the organization of the contact point has a best value. The point of the height and pick the ball institutions can achieve maximum distance, and the position of the ball fulcrum makes the lift distance and the lift height maximization produce different places, so we can't thought set lift ball point to satisfy the high altitude and the maximize the farthest distance at the same time. Electromagnet for height and the distance of the influence is linear, so we should as far as possible to improve the average output power electromagnets. According to the front of the quantitative analysis, set to pick the ball distance as far as the objective function is as follows:

$$
\max F(X)=\left[\frac{-2}{m_{c}+m_{b}}\left(m_{c} g(l-h)(1-\cos \alpha)+m_{b} g r(\sin (\phi+\theta+\psi)-\sin (\phi+\theta+\psi+\alpha))-W_{k}\right] \frac{\sin (2 \beta)}{g}\right.
$$

Design variable $X=[\beta, l, H]^{\mathrm{T}}$. Set constraint conditions: shot out angle $45^{\circ}<\beta<90^{\circ}$; Pick the ball institutions fulcrum height $0.049 \mathrm{~m}<l<0.59 \mathrm{~m}$; lift the ball institutions and the ball the contact point high $0 \mathrm{~m}<H<0.049 \mathrm{~m}$. The optimization mathematical model belongs to the constraint single-objective nonlinear optimization problems. Choose SUMT penalty function method to get the best value for all variables, this method through the tectonic augmented objective function, and the constraint optimization problem into a series of unconstrained minimization problems, through a series of questions to solve constraint and to get original constrained problems optimal solution. Definition function is:

$$
F(x, a)=f(x)+a \sum_{i=1}^{m}\left[\max \left(0, g_{i}(x)\right)\right]^{2}
$$

The initial plan for $x^{0}=[45,0.049,0]^{\mathrm{T}}$. After 17 iteration calculation, and get the optimal solution: $l=0.043 \mathrm{~m}, H=0.0038 \mathrm{~m}, S_{\max }=4.38 \mathrm{~m}$

\section{Test results}

Put the calculations parameters into Matlab ball movement track simulation, the results shown in Figure1 (a). Among them, the longest flight distance is $4.312 \mathrm{~m}$, top flight is $1.102 \mathrm{~m}$, and the flight time is 0.896s. In physical experiment, with corresponding image processing program acquisition lift the ball a parabolic height and distance data, through the parabolic curve fitting the obtained data see Figure 1 (b) and (c)

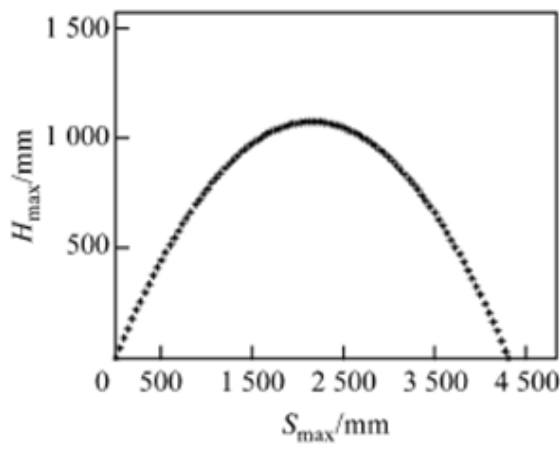

(a) The theoretical curves

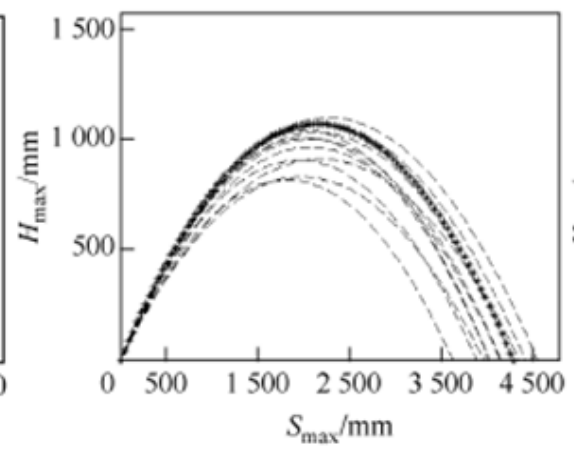

(b) chip kick mechanics

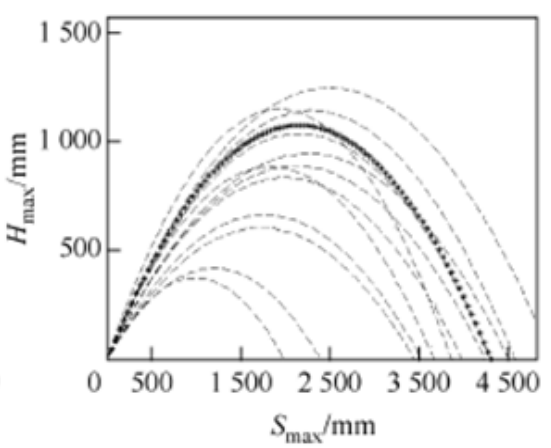

(c) No chip kick mechanics

Fig.1. The experimental results

The ability of pick the ball robot has reached theoretical calculation expected. The experiment started with no the institutions, the ball can not very well joint with pick cue, causing pick the ball dynamics change range is very large, and pick the ball height and the average of the theoretical calculation of the distance is smaller than the calculated assumption the height and distance.

After the ball add tape loading agencies, institutions force the ball the reverse spin, the ball close to pick the cue, pick the ball transfer fully energy to the ball, pick the ball effect is obvious stable. But it is found that the actual pick the ball after add tape loading agencies less than the 
theory calculated average distance.

\section{Conclusion}

Based on the analysis of the mechanical theory as the foundation, designed the soccer robot pick the ball institutions optimal design process, found aim function, select design variables and the corresponding optimization algorithm to optimize a complete set of institutions. At last through the test to get the final performance parameters of the institution. Experiments show that the system has higher accuracy and stability, the new optimize pick the ball have design basic requirements, and achieved good ideal control effect.

\section{Acknowledgement}

In this paper, the research was sponsored by the Nature Science Foundation of Henan Province (Project No. 201112400450401) and Youth Fund Project of Luoyang Institute of Science and Technology (Project No. 2010QZ16).

\section{References}

[1] Satoshi Kagami,Tomonobu Kitagawa,Koichi Nishiwaki,Tomomichi Sugihara,Masayuki Inaba,Hirochika Inoue. A Fast Dynamically Equilibrated Walking Trajectory Generation Method of Humanoid Robot [J], 2002.

[2] HIROKIK, MINORUA, YASUOK, ET al.RoboCup: a challenge problem for AI and robotics. HirokiK. RoboCup-97: Robot Soccer World Cup [C]. Berlin: Springer, 1998.38-43.

[3] Zhizhong Yin. Application of FPGA control DC motor servo system [J]. Inner Mongolia Science and Technology and Economy, 2008177 (23) 101-103.

[4] Joerg Christian Wolf, Phil Hall, Paul Robinson, Phil Culverhouse. Bioloid based Humanoid Soccer Robot Design, 2007.

[5]Wu Chuan-yu, He Lei-ying, Design and Realization of Instructional RPPR-Robot, Research and Exploration in Laboratory.2007, 26(10)

[6] Nishiwaki K,Kagami S. High Frequency Walking Pattern Generation based on Preview Control of ZMP, IEEE International Conference on Robotics and Automation. 2006.

[7] Chen Nan and so on. For the field of industrial and highly interconnected, TI launched a new Sitara ARM9 microprocessor. [J]. Global Electronics, 2010 (5) 86-87.

[8] Vision Heading Navigation Based on Navigation Curve [A]. Proceedings 2010 International Conference on Intelligent Computing and Integrated Systems[C]. 2010.

[9] Chen Nan and so on. For the field of industrial and highly interconnected, TI launched a new Sitara ARM9 microprocessor. [J]. Global Electronics, 2010 (5) 86-87.

[10] Jonghoon ZMP Park,Youngil Youm.General ZMP Control for Bipedal Walking. IEEE International Conference on Robotics and Automation. 2007.

[11] Chunmei Xu. Mechanical servo system based on fuzzy neural network for complex control [J]. Control Engineering .2010:17 (2):146-148.

[12] Zhijun He. LM629-based motor servo control system design [J]. Mechanical design and manufacture .2009 (2) 40-42. 